\title{
Study of coercive measures in prisons and secure psychiatric hospitals: the views of inmates and caregivers*
}

\author{
A Runte-Geidel ${ }^{1}$, E Girela², Á López ${ }^{3}$, F Ruiz ${ }^{4}$, F Torres-González ${ }^{5}$ \\ ${ }^{1}$ Departamento de Pedagogía. Universidad de Jaén. \\ ${ }^{2}$ Departamento de Medicina Legal y Forense. Universidad de Córdoba \\ ${ }^{3}$ Hospital Psiquiátrico Penitenciario de Alicante \\ ${ }^{4}$ Centro Penitenciario de Albolote. Granada \\ ${ }^{5}$ CIBER de Salud Mental, CIBERSAM. Universidad de Granada
}

\section{ABSTRACT}

Aim: The aim of the study was to ascertain the opinions of both inmates and staff of prison establishments about the use of coercive measures justified for clinical reasons for people with mental health problems and about the need to create protocols to regulate the application of these measures.

Method: These opinions were gathered in a Qualitative Study with Focus Groups (prison inmates and prison staff) from the Granada Penitentiary Centre and the Alicante Penitentiary Psychiatric Hospital, both in Spain.

Results: The results showed that forced medication is the most commonly used coercive measure in these institutions. The inmates did not understand and rejected the use of this measure, above all because they were poorly informed about their illness and the medication required to treat it. The staff however defended the benefits of psychiatric medicine, even when administered without the patient's consent.

Conclusions: Both inmates and staff agreed that it would be useful to have a protocol regulating the use of coercive measures. The study has also identified a number of important factors that could help to reduce the need for coercive measures or make their use unnecessary.

Keywords: Mental health; Prisons; Patient rights; Psychiatry; Spain; Qualitative Analysis; Pharmacology; Protocols.

\section{ESTUDIO DE LAS MEDIDAS COERCITIVAS EN CENTROS PENITENCIARIOS Y HOSPITALES PSIQUIÁTRICOS PENITENCIARIOS: OPINIONES DE INTERNOS Y PROFESIONALES.}

\section{RESUMEN}

Objetivos: El estudio ha pretendido conocer por un lado la opinión de personas internas en establecimientos penitenciarios, y por otro lado, la opinión de los funcionarios de estas instituciones sobre el uso de medidas coercitivas por indicación clínica en personas con problemas de salud mental y sobre la necesidad de creación de protocolos de actuación para la aplicación de estas medidas.

Metodología: Estudio cualitativo que ha utilizado la técnica de Grupos Focales llevados a cabo con internos y funcionarios del Centro Penitenciario de Granada y del Hospital Psiquiátrico Penitenciario de Alicante, España.

Resultados: Los resultados demuestran que la medida coercitiva más utilizada en estas instituciones es la medicación forzosa. Las personas internas no comprenden y rechazan la utilización de esta medida, sobre todo porque están mal informadas sobre su enfermedad y su tratamiento farmacológico, pero los profesionales abogan por los beneficios de la medicación psiquiátrica, aunque sea de forma involuntaria.

*Pueden consultar la versión en español en la página web de la RESP www.sanipe.es 
Conclusiones: Tanto usuarios como profesionales están de acuerdo con la utilidad de la existencia de un protocolo de actuación para la aplicación de medidas coercitivas. Este estudio ha hallado importantes factores que podrían ayudar a disminuir la utilización de medidas coercitivas o incluso evitarlas.

Palabras clave: Salud mental; Prisiones; Derechos del paciente; Psiquiatría; España; Análisis Cualitativo; Farmacología; Protocolos.

\section{INTRODUCTION}

Although coercive measures are frequently used in psychiatry as a part of clinical practice, above all in hospitalizations and emergency psychiatric services, this subject has not been studied in depth and the Member States of the European Union only recently acknowledged that there was an urgent need for this question to be regulated in $\mathrm{law}^{1}$. Even less research has been done on psychiatric patients held in penitentiary establishments ${ }^{2}$.

On exceptional occasions, hospitalization in psychiatric units requires that certain measures be taken that could harm fundamental rights such as dignity, freedom or privacy, if the right precautions are not taken. These measures (involuntary committal to Health Service hospitals, forced treatments, physical restraint, and isolation) may be necessary, temporary instruments in the handling of certain episodes in a patient's illness, but they require specific regulation that goes beyond the generic protection of fundamental rights and the legal requirement to obtain the patient's consent. This requirement is often ignored or bypassed either because consent cannot be obtained in a valid manner, or because the patient refuses to give his/her consent and the measures are taken against their express wishes, in breach of applicable legislation (Spanish Law 41/2002 on the Autonomy of the Patient).

It is often difficult to obtain the consent required for this treatment due to the relatively common poor insight of the patient due to the illness itself and the grey area of varying patient autonomy. The boundaries that mark out the competence of the patient to consent to the treatment they are to receive are necessarily flexible in the case of people who are mentally ill, but are at times confusing. The fact that a patient has poor insight of his/her illness does not always imply that they are clearly incompetent to take decisions regarding their treatment. In non-psychotic pathologies, such as eating disorders, drug addiction or personality disorders, the problem is even more complex ${ }^{3}$. Nowadays the mechanical restraint of patients is used in ways that minimise suffering and is performed under medical supervision.
Alerted by the frequent use of coercive measures on hospitalized patients and alarmed by the lack of any legal regulation of their use, a consortium of European researchers from 12 different countries launched the EUNOMIA project, which aimed to contribute to the harmonization of good clinical practice in the use of coercive measures by therapeutic indication ${ }^{1,4}$. The EUPRIS Project, in which Spanish researchers are involved ${ }^{2}$, was developed in a similar way. It were financed by the European Commission and its final report set out a series of basic indicators of mental health in prison.

The COCEHOSPE Project continues and extends these studies by investigating the question of the coercive measures taken by medical indication in prisons. Very little research has been published that presents the opinions of the different parties involved in the use of coercive measures. In a study by the Department of Psychiatry of Weissenau in Ulm, Bergk $\&$ Steinert ${ }^{5}$ reported that medical staff preferred to use isolation, as they considered it to be less restrictive in terms of human rights. Patients interviewed by Lidz et $\mathrm{al}^{6}$ identified health personnel as the group that took most coercive measures during admission to hospital, and stated that both verbal and physical coercion were used to put pressure on patients to accept their admission to hospital.

In the initial phase of the COCEHOSPE Project, we used the focus group technique as a means of comparing and contrasting the opinions expressed by the different collectives involved as either active or passive subjects in the application of coercive measures in prisons and similar institutions. The coercive measures covered by this study were those justified only for clinical reasons and include isolation, chemical coercion, forced medication and physical coercion (physical or mechanical restraint).

\section{MATERIAL AND METHODS}

This study was undertaken with the authorization of the General Directorate for Penal Institutions and was approved by the Ethical Commitee of the Main 
Researcher's Institution. Furthermore, all the participants signed an Informed Consent form.

\section{Population:}

Sampling for this study was based on two participant profiles (Table 1): Profile 1 was called "Inmates" and was made up of inmates from the Granada Penitentiary Centre and the Penitentiary Psychiatric Hospital in Alicante, to whom coercive measures had been applied for clinical reasons. Profile 2 was called "Caregivers" and was made up of members of the staff of these institutions, including both health and non-health personnel.

Exclusion Criteria (for the two groups in Profile 1):

- Inmates who were subject to coercive measures of isolation or mechanical restraint for reasons relating to the prison regime and not for medical reasons.

- Inmates who were subject to coercive measures for medical reasons that were not related to their mental disorders (for example respiratory isolation of TB patients).

\section{Methodology:}

This stage of the study was conducted using a qualitative methodology known as the Focus Group Technique. This method is particularly appropriate when the objective is a profound understanding of the phenomenon being investigated, from the point of view of the people directly involved or affected by it ${ }^{7}$. Focus Groups (FG) typically revolve around a conversation between members of a small group of people (6 to 10 members).

\section{Focus Group Sessions}

The meetings of the groups were organized by two researchers from the study team and were recorded on audio and video. The conversations were then transcribed and typed up in preparation for analysis. Tables 2 and 3 show the characteristics of the participants in the FG.
Table 2. Caregivers profile by profession.

\begin{tabular}{lll}
\hline & \multicolumn{1}{c}{ Health Prof. } & Non- Health Prof. \\
\hline Group 2 & $\bullet 2$ General Practitioners & $\bullet 2$ Prison Officers \\
& $\bullet 1$ Nurse & \\
& $\bullet 1$ Auxiliary Nurse & \\
\hline Group 4 & $\bullet 1$ Psychiatrist & $\bullet 1$ Attendant \\
& $\bullet 1$ General Practitioner & $\bullet 2$ Prison Officers \\
& $\bullet 2$ Nurses & $\bullet 1$ Teacher \\
& $\bullet 1$ Auxiliary Nurse & $\bullet 1$ Pharmacist \\
\hline
\end{tabular}

Table 3. Patients main Characteristics.

\begin{tabular}{|c|c|c|}
\hline & Gender & Main diagnosis \\
\hline Group 1 & $\begin{array}{l}\text { - } 6 \text { Men } \\
\text { - } 1 \text { Woman }\end{array}$ & $\begin{array}{l}\text { - } 2 \text { Schizophrenia Paranoid type } \\
\text { - } 1 \text { Schizophrenia undifferentiated } \\
\text { - } 1 \text { Delusional disorder } \\
\text { persecutory type } \\
\text { - } 2 \text { Drug-induced psychosis } \\
\text { (cocaine) } \\
\text { - } 1 \text { Bipolar disorder }\end{array}$ \\
\hline Group 3 & • 6 Men & $\begin{array}{l}\text { - } 3 \text { Schizophrenia Paranoid type } \\
\text { - } 2 \text { Schizophrenia undifferentiated } \\
\text { (one of them + personality } \\
\text { disorder not otherwise specified) } \\
\text { - } 1 \text { Borderline personality disorder }\end{array}$ \\
\hline
\end{tabular}

\section{Themed scripts}

The FG were conducted using scripts that had previously been prepared by researchers from the project team. These scripts came in the form of lists of questions that were used only as a prompt for the person chairing the group sessions. Two different scripts were used, one for each participant profile.

The Analysis strategy and the interpretation of results were performed according to the objectives of the study in 3 stages: 1) Analysis of the video footage focussing on the attitudes of the participants, their level of participation, verbal and non-verbal communication. 2) Preliminary analysis: Comprehensive reading of the transcripts of the focus group sessions and their segmentation into smaller units. 3) Analysis of content: definition of the analysis categories, categorization of the different segments of text, preparation and interpretation of the results.

Table 1. Segmentation of the Focus Groups (FG).

\begin{tabular}{lll}
\hline Participant profiles & Type of groups & Penitentiary centres \\
\hline Profile 1 & Groups 1 and 3 & FG 1: Inmates from PPH in Alicante \\
& FG 3: Inmates from Granada PC \\
\hline Profile 2 & Groups 2 and 4 & FG 2: Caregivers from the PPH in Alicante \\
& & FG 4: Caregivers from the Granada PC \\
\hline & \\
&
\end{tabular}




\section{RESULTS AND DISCUSSION}

The results are grouped in relation with the corresponding categories of analysis. We present them according to the two profiles: inmates and caregivers. You might see first the inmates' discourse, followed by the caregivers' ones.

\section{Profile 1: Inmates}

\section{Category 1: Opinions about the medical treatment re- ceived at this Institution}

The inmates' opinions of the doctors and psychiatrists varied according to the particular institution in which they were interned. The inmates from the prison offered varying opinions. Some were essentially neutral in their attitude, while others said that they were dissatisfied with the way in which they were treated. The participants from the hospital group expressed more favourable opinions about the treatment they received.

The fact that in general the inmates had a higher opinion of the staff from the PPH could be due to the fact that in the Hospital the inmates are considered as "psychiatric patients", and instead of serving a sentence are confined in a secure hospital as a security measure. This is because their mental condition means that they cannot be accused or held responsible for the crimes committed. We think that in this context, patients, doctors and caregivers are more aware of the illness and that medical considerations prevail over a strict control-based approach. An additional factor that could predispose inmates against doctors is that narcotics consumption is very high and many inmates are multiple drug-users. This means that they frequently ask their doctors for short and medium-acting Benzodiazepine type drugs and obviously are unhappy when the doctors refuse to prescribe them.

Some of those interviewed thought that their appointments or meetings with the psychiatrist were too short, and that as a result the psychiatrist did not know them well enough and could not understand their problems or needs in any great depth. They claimed this lack of time also influenced the type of treatment they were offered, and suggested that if the psychiatrists had more time they could use other forms of therapy in addition to medication.

Some participants blamed the fact that medical staff did not have sufficient time to attend to their needs on the Government/Authorities and the limited human resources they provided.
The fact that the inmates had just a few minutes' contact with the medical staff could also explain their general lack of information about their illnesses or the treatment they received. This lack of information created a sense of insecurity in that they did not know what was happening to them or why the doctors insisted so much on the importance of the medication. This insecurity led to a greater likelihood of rejection or fear of the pharmacological treatment. These opinions suggest that the patients do not have an especially negative view of the health professionals and to some extent they excuse them for any shortcomings in the attention they receive, preferring to lay the blame on the Institution.

The inmates who participated in the focus groups also highlighted the need to improve the training and assessment of the prison officers who attended to them ${ }^{8}$.

\section{Category 2: Opinions about the coercive measures used}

Two main coercive measures were mentioned by the participants in the two groups, namely the administration of drugs by injection against their wishes and physical restraint. Some said that they agreed with such measures, which in certain cases they considered necessary and even beneficial for the person concerned. Others seemed to be afraid of the injections and said that they preferred mechanical restraint. However, most of them either did not understand the reasons behind the treatment they received or did not agree with it. This may be due to the fact that nowadays mechanical restraint is applied only in very specific situations and less frequently, whereas the continued use of medication (at times against the patient's will) is something that affects them on a daily basis. To some extent this is changing, as the patients tend to talk about their experiences in the past tense and when they complain about side-effects they are referring normally to mixtures of injectable atypical antipsychotics or depot medications, while the new treatments (above all when agreed with the patients) are better tolerated and accepted by the patients. However, it is important to point out that the majority of those interviewed are psychotic patients who on the one hand have only a limited awareness of their illness and on the other require continued use of medication in order to avoid episodes that could cause them more serious harm.

The participants also referred to occasions on which they felt that medication had been used in excess. They remembered cases in which they or other prisoners had received large amounts of medication 
that had very unpleasant and even dangerous physical side-effects.

In addition, those interviewed also felt that they were subjected to coercive measures or to the use of medication for excessively long periods. The information they received about what was happening to them seems to be important again here. It was either insufficient or too complicated to understand.

The inmates also recounted situations in which the coercive measure was accompanied by physical and verbal violence. They felt angry about these actions but also expressed a feeling of impotence and submission. Nurse et $\mathrm{al}^{8}$ also found that the inmates were unhappy about the verbal ill-treatment received from some staff.

When we asked about possible alternatives to these coercive measures, or something that would avoid reaching the point at which these measures became necessary, the participants again raised the need for different therapies and also for leisure activities and other alternatives to enable them to occupy their time creatively. The inmates interviewed in the study by Nurse et al ${ }^{8}$ also emphasized that the fact that were few activities in prison that stimulated them, either physically or mentally, something that made them feel more stressed and irritated.

They were finally asked what they thought about the possibility of creating a protocol to regulate the application and use of coercive measures. Most of them viewed this idea positively in that it would protect them from the excesses referred to above.

\section{Text Box 1: Profile 1 - Inmates.}

"It's just like what that lad was saying, if a psychiatrist arrives and he's got like 40 or 50 patients, what he does is pills, pills and more pills". (Inmate PC)

"Well, my opinion is that they devote very little time to us, because in ten minutes each month or every three weeks, in the ten minutes, or five minutes that the appointment with the psychiatrist lasts, I don't think you can find out much about someone's personality". (Inmate PPH)

"When some people, some people have an episode, the solution is 4, 5, 10 injections and some of them have ended up in hospital and been left paraplegic". (Inmate PPH)

"Well yes, they should exist (the protocols), at least so that they don't go too far, like they do in some cases. Don't you think?" (Inmate PC)

"As far as I can see, the therapy should try to find the source of whatever it is that is winding us up, that gets us going, that make us get nervous, and perhaps causes certain abuses, or ill-treatment, or to the things around us... (Inmate PPH)

\section{Profile 2: Caregivers}

Category 3: Opinions about the most useful ways of treating certain psychiatric illnesses, including ways that can be applied inside Prison

Both groups of caregivers expressed the idea that penitentiary institutions ( $\mathrm{PC}$ and $\mathrm{PPH}$ ) are not the best context in which to attend to the mental health problems of inmates. However, the staff from the PC were less emphatic on this question, in that they considered that some people are better off in prison than outside where they receive less medical and psychiatric attention and in some cases less attention from their families. In fact many of these patients suffer from the comorbidity of mental illness and drug abuse, which makes them extremely difficult to deal with and can lead to the loss of family support. Their social background is another important factor in that when the inmates leave prison they return to marginal areas of social exclusion often outside the safety net provided by the health system. They stated that the inmates are well cared for, that they receive the daily medication that they require and that there is greater control to ensure that they follow their treatment as prescribed.

Category 4: Opinions about the criminal responsibility of psychiatric patients that have committed offences

In general the staff from the two institutions agreed on the idea that the crime had to be considered more important than the illness, in other words that those who have committed a crime have to answer for it, either in prison or in a prison hospital. The fact that most of the staff of these institutions consider that the inmates, be they mentally ill or not, are there because they deserve a punishment, in other words to pay for the crime they have committed, reveals an internal attitude towards these people which in certain circumstances may influence the decisions they take in relation to the use of coercive measures, or the behaviour and manners of those who apply such measures.

\section{Category 5: Opinions about the possibility of deciding to apply a medical treatment without first ascer- taining the opinion of the patient or applying it against his/her will}

Most of the caregivers interviewed in this study stated that they agreed with the need to use coercive measures in cases in which such measures are indicated for medical reasons. As happened with the inmates, the caregivers were also divided between 
those who preferred to use medication as a form of restraint in cases of agitation or psychotic episodes, most of whom were health professionals, and others, including prison officers and attendants, who defended the use of physical restraint. Unlike the patients, most caregivers prefer the use of medication as they believe it can help avoid psychotic episodes and the consequent harm to the patient, and other episodes of conflict or even violence, an aspect highly rated by non-medical caregivers.

On this question, the health professionals from the PC defended the continued use of psychiatric medication as a means of preventing episodes of violence, aggressiveness and self-harm. Health professionals also believed that a continued use of medication would avoid the need for certain coercive measures, even if on many occasions the medication itself was administered against the wishes of the patient. The health professionals also stressed that as psychiatric medication avoids patients suffering psychotic episodes, it also prevents the physical and mental deterioration caused by such episodes. They felt that often it was difficult for mentally ill people to understand the benefits of their medication.

The health professionals also made a hierarchical differentiation between the forced use of different measures. They clearly stressed that they would prefer to force patients to take the medication than run the risk of a more serious decompensation in which they would have to resort to physical restraint or isolation. They argued that the use of measures such as isolation and physical restraint has declined a lot in recent years in line with the progress made in medication and the option to use chemical restraint, either continuously or in large doses during psychotic episodes. However, they feel that the patients prefer mechanical restraint to chemical restraint, because they are aware of the unpleasant side effects of the drugs administered in these situations.

The measures involving isolation were described mainly by staff from the PC, who also said that these measures were replaced whenever possible by medication, even if this had to be administered against the wishes of the inmate concerned. They justified the use of chemical restraint because it also helped reduce the time during which the inmate had to be physically restrained.

In the same way, prison officers and non-health professionals revealed that they tried to use other means to convince patients to continue with their medical treatment. Some resorted to what they described as blackmail, others tried to convince them by talking to them and by using the good relationship they had built up with certain inmates. The most frequent complaint made by these professionals was their lack of training and preparation for dealing with these situations and in general with people with mental health problems.

\section{Category 6: Opinions about the need for protocols to regulate these matters}

There were quite varied opinions about the need for protocols on the use of coercive measures. Some healthcare professionals were more negative about this idea because they felt it would limit their capacity to take independent decisions, others said that these protocols could protect them, as they would legitimize their actions and provide better information and instruction as to how to act in different situations, and that they would also define the responsibilities of each professional involved. Others however believed that a protocol of this kind might increase the use of coercive measures. Nevertheless most believed that a protocol would be positive and beneficial for both the patients and the professionals involved, from the point of view of both the indications for and the application of coercive measures.

\section{Category 7: Opinions as to whether other measures might reduce the need for coercive treatments}

The opinions about other resources that might reduce the use of coercive measures were similar to those expressed by the inmates. In general they referred to the need for more and better leisure and free-time activities, and to the fact that there were other therapeutic resources that offered alternatives to pharmacological treatment. Above all they highlighted the need for a change in methods or approaches to treatment in the sense of making psychotherapy more widely available and the need for staff to listen to the inmates carefully.

Some believed that by improving staff training in certain skills, such as communication and conflict resolution, they could in some cases reduce the need to restrain the patient in order to administer medication. Similarly, the staff who participated in the focus groups in the research by Nurse et $\mathrm{al}^{8}$ stated that the lack of information about mental illnesses, and the lack of training in communication and management skills had a negative influence on their attitude to their work.

Other factors such as physical and environmental conditions may also contribute to reducing the number of situations that give rise to aggressive behaviour and "friction" between patients, so reducing the need for staff to intervene. 
Finally, the staff expressed the view that better contacts were required with professionals from outside their institutions, for example in the cases of patients being admitted to hospital or being released at the end of their sentence. The study by Scheyett et $\mathrm{al}^{9}$ also found that there were serious problems of communication between mental health services in the community and in the prisons they studied. They defended the need for effective coordination between health professionals working inside and outside prisons as a way of improving the treatment of the mental health problems suffered by these people.

Text Box2: Profile 2 - Caregivers

"I think my actions as a prison officer are more justified if I have to restrain him or immobilize him because he has attacked somebody or if he is aggressive than when I have to take hold of him and oblige him to have an injection against his wishes. It's not the same, is it?" (Caregiver PPH)

"Well of course, we prefer that when the person is seventy or eighty years old, well, or sixty, or even people of thirty, that the medication causes them as little damage as possible". (Caregiver PC)

"These are things that happen anyway, but well they are not ...., I don't think it would be a bad idea for them to be put down on paper and that they are clearly specified (the protocols)... that they are clearly specified. I think that would be good. The thing is that these are very exceptional circumstances, aren't they?" (Caregiver PC)

"The psychiatric patient in prison is not going to be here all his life, there must be some lines of interaction between the health teams on the outside and those working inside so as to provide some form of continuity in terms of attention, treatments etc. " (Caregiver PC)

\section{CONCLUSIONS}

Before presenting the conclusions in relation to the objectives of this research, it is essential to make clear that the findings produced by a qualitative research study cannot be generalized, which means that the opinions presented here cannot be interpreted as being those of the majority of the staff of Spanish penitentiary institutions, or of the inmates of these establishments. These opinions may be considered as representative of these collectives and may serve as a guide for new paths in quantitative research. They may also add depth and substance to the statistical data to be obtained in subsequent stages of this study.

The coercive measure that gave rise to the greatest differences of opinion between the staff and the inma- tes was the use of forced medication. Whereas the former considered that this measure was necessary and useful, the latter neither understood nor accepted it.

In the opinion of the staff the use of coercive measures is fully justified by the fact that some prisoners suffer psychotic episodes and as a consequence may present a danger to themselves or others. These professionals support the continued use of pharmacological treatment, even when administered forcibly, as a means on the one hand of avoiding such episodes, so preventing the damage they cause to patients, and on the other of preventing fights and physical aggression. In addition, the staff felt that the continuous use of medication reduced the need for more drastic measures such as isolation or physical restraint of the patient. Although this was the majority opinion, others thought that medication was prescribed too often.

Although the patients agreed with the use of coercive measures in certain circumstances, they preferred physical to chemical restraint, because of the side effects caused by the drugs administered in these situations. They also rejected the use of forced medication, above all when the psychotic episode or crisis had been resolved. In any case the patients are more likely to accept the medication when the treatment is agreed in advance with the doctor in an attempt to minimize the particular side-effects experienced by each inmate.

All the participants agreed that more human and material resources were required, and that complementary activities which lead to improvements in the quality of the treatment given to the patients of these institutions should be promoted. They concluded that these measures would help to reduce the need for the use of coercive measures.

Finally, both caregivers and inmates agreed that the establishment of a protocol regulating the use of these measures was a positive, necessary idea.

\section{ACKNOWLEDGEMENTS}

The study was supported by a grant (PI070862) from the Spanish Fondo de Investigaciones Sanitarias (Health Research Fund).

\section{CORRESPONDENCIA}
A Runte-Geidel
Departamento de Pedagogía. Universidad de Jaén. Campus las Lagunillas, s/n. 23171. Jaén, Edificio C5. arunte@ujaen.es 


\section{REFERENCES}

1. Kallert TW, Glöckner M, Onchev G, Raboch J, Karatergiou A, Solomon Z, et al. The EUNOMIA project on coercion in psychiatry: study design and preliminary data. World Psychiatry. 2005; 4: 168-72.

2. Salize, HJ, Dressing, H, Kief C. Mentally Disordered Persons in European Prison Systems - Needs, Programmes and Outcome (EUPRIS). Final Report. Mannheim, Central Institute of Mental Health; 2007.

3. Camacho M. Restricción de la libertad del enfermo mental. Indicaciones psiquiátricas y su valor terapéutico. En: Medina A, Moreno MJ, Lillo R, editores. El Psiquiatra: del ámbito médico al jurídico. Libro de ponencias de las II Jornadas de Encuentros Jurídico-Psiquiátricos; 6-7 de octubre de 2006; Córdoba, España. Madrid: Fundación Española de Psiquiatría y Salud Mental; 2007. p. 233-46.
4. Kallert T, Torres-González F. Legislation on coercive mental health care in Europe. Frankfurt: Peter Lang; 2006.

5. Bergk, J, Steiner T. Staff members attitudes towards coercive measures. Communication presented at WPA Thematic Conference - Coercive Treatment in Psychiatry: A comprehensive review. Dresden (Germany), 6th - 8th June; 2007.

6. Lidz CW, Mulvey EP, Hoge SK, Kirsch BL, Monahan J, Bennett NS, et al. Sources of coercive behaviours in psychiatric admissions. Acta Psychiatrica Scandinavica. 2000; 101: 73-9.

7. Flick U. Introducción a la investigación cualitativa. Madrid: Ediciones Morata; 2004.

8. Nurse J, Woodcock P, Ormsby J. Influence of environmental factors on mental health within prisons: focus group study. British Medical Journal. 2003; 327 (Aug 30): 480-3.

9. Scheyett A, Vaughn J, Floyd-Taylor M. Screening and Access to Services for Individuals with Serious Mental Illnesses in Jails. Community Ment Health Journal. 2009; 45: 439-46. 